\title{
Research on the Corporate Cultural Strength, Employee Behavior and Organizational Performance --An Empirical Study on the Culture of SMEs in Guangxi Province,China QIUXUE LUO
}

\author{
Panyapiwat Institute of Management, Thailand \\ chinasnow2010@gmail.com
}

\begin{abstract}
Keywords: Corporate cultural strength; Employee behavior; Organizational performance; Empirical study
\end{abstract}

\begin{abstract}
To understand the relationship among the corporate cultural strength, employee behavior and organizational performance and based on the previous research results, this paper obtains the relationship among the three variables and proposes hypotheses about the relationship among them. This paper collects data on SMEs in Guangxi Province through 500 questionnaires and got 384 effective questionnaires, and then tests the hypotheses through data analysis by SPSS 22.0 and AMOS 20.0, finally found that Corporate cultural strength is positively related to employee behavior and organizational performance; Employee behavior is positively related to organizational performance; Employee behavior plays an intermediary role in the relationship between corporate cultural strength and organizational performance.
\end{abstract}

\section{Introduction}

Organizational performance is the core of the organization theory and strategic analysis, and it has been valued by people since the 1980s, which is also a hot topic in the field of management. Organizational performance is a key element of business management engaged in an important relationship with corporate culture construction, which is a key link of corporate culture construction, and its specific contents change over time. Rousseau (2001) proposed a relatively complete psychological contract formation model, indicating that the essence of corporate culture is to shape a psychological contract, so that personal values of employees and integration of psychological factors are closely related to business development, thus playing a subtle but crucial role in the long-term operating performance in the enterprise. Therefore, this paper believes that while exploring the relationship between corporate cultural strength and organizational performance, behavioral factors of employees shall be taken into account. Employee behavior is an important form of manifestation in terms of individuals, and the formation of individual behavior is affected by corporate cultural strength and is also related to organizational performance.

\section{Theoretical foundation and research hypothesis}

As a sub-system of the corporate comprehensive competitiveness system, corporate cultural strength is also an integrated system that includes different factors. It is the dynamic vitality formed by these different factors that plays an important role in the development of enterprises and society (Denison, 2005). To help enterprises improve cultural strength, scholars at home and abroad start to study the system that constitutes corporate cultural strength. Mainstream theories mainly include: Three-dimensional concentric circle theory, four-dimensional structure theory and five forces theory. If an enterprise wants to really maintain a lasting competitive advantage, it has to constantly improve its abilities, and the key to improving its abilities is to constantly improve corporate cultural strength, which determines strength of core abilities of the enterprise.

The research on employee behavior is the most common in the field of organizational behavior, which directly determines the effectiveness of organization. For enterprises, both goals and benefits shall be achieved through employee behavior. People are subjects and objects of corporate cultural 
strength, and cultural strength is people-oriented and takes people as carriers of behavior. Corporate cultural strength is achieved by employees and reflected in the specific behavior of employees. Cascio (1991) points out that it's a common method to use subjective methods to measure individual behavior in the field of organizational behavior. Employee behavior mainly focused on by subjective measurement methods includes organizational commitment, organizational citizenship behavior, turnover intention, etc., which are vital for employees to show good performance. At the same time, it's also the focus of the field of practice.

Performance means display or achievements, and performance is the prerequisite for the existence and development of organization and an important core of management practice and theories. Peter Drucker, a master in management, believes that performance is the "direct result" in his book of The Effective Executive. Opinions on performance are mainly divided into three kinds: (1). Performance is evaluated based on results; (2). Performance is evaluated based on behavior; (3). Performance is evaluated based on behavior and results. Bernadine et al. (1995) believe that "performance is the achievement and result of work, because these achievements and results are closely related to strategic goals of enterprises, customer satisfaction and return on invested capital". Therefore, organizational performance can be defined from different perspectives. However, in general, organizational performance measures realization of goals by enterprises, and it's the result displayed at different levels to realize goals, which mainly refers to the performance achieved in a certain period of time by the entire organization.

Nie Qingkai and Zhao Qing (2008) points out that corporate cultural force is the "core" embedded in organizations, technologies and management of the enterprise, which is closely related to enterprise performance. Corporate cultural strength can improve the production efficiency, reduce trading costs, increase the brand value and increase the value of products, thus enhancing the competitiveness of the enterprise. Corporate cultural strength bring tangible and intangible, economic and social benefits to the enterprise, indicating that corporate cultural strength is an effective means to obtain economic growth (Nie Qingkai, He Haoming, 2012). Chen Chunhua (2016) believes that corporate culture is the internal driving force for the sustainable development of the enterprise, playing a very important role in promoting the enterprise to achieve good performance. Excellent corporate culture can sort out the difference in the internal value of the organization, improve the operating efficiency of the organization and enhance organizational commitment and team morale. Corporate cultural strength relies very much on the path of enterprise development (Nie Qingkai, Zhao Qing, 2008). Therefore, this research proposes the hypothesis H1: Corporate cultural strength is positively related to organizational performance;

Wang Qin (2012) believes that corporate cultural force shall be displayed through the ideology and behavior of employees. On the one hand, corporate cultural force enables employees to recognize their role in the overall development strategy of the enterprise and internalize corporate vision, values and goals into values and awareness that guide their behavior to achieve the unity between the enterprise and individuals; On the other hand, this internalized corporate cultural strength is bound to restrain employees as individuals from putting the interests of the enterprise in an extremely important position, and when behavior is inconsistent with the standards, it can be corrected and overcome in time. Leaders effectively shape the corresponding cultural standards and transform them into management and employee behavior (Brockbank, Ulrich \& Yakonich, 2002). Yang Hongchang (2003) stresses that deep corporate culture that really drives employee behavior is very important. Zhang Min, Chen Chuanming (2005) conclude that corporate culture affects the behavior of the enterprise by guiding the behavior and values of members of the enterprise, while people are the most responsive, adaptable and imaginative basic elements in the organization, and the efficiency of any behavior of the enterprise will be subject to the behavior of its members. After all, corporate culture is created by people in practice, and people are closely related to the cultural environment of the enterprise (Li Minghua, 1993). Through employee behavior, values and ideas of the enterprise become things that can be touched and felt; through employee behavior, customers 
and society can clearly understand corporate culture. Therefore, this research proposes the hypothesis $\mathrm{H} 2$ : Corporate cultural strength is positively related to employee behavior.

In the 1980s, with the rise of the corporate culture theory, William G. Ouchi (1984) proposes Theory $\mathrm{Z}$ based on humanistic management, emphasizing the influence and effect of organizational support, organizational climate and employee relations on employee productivity. This theory has been supported in the empirical test, which specifically includes the following factors: Organizational commitment, organizational or executive support, transformational leadership, organizational climate, working environment and conditions, authorization, remuneration fairness, corporate system, corporate culture, etc. (Wang Zhen, Song Meng, Sun Jianmin, 2014). Qu Qing and Gao Ang (2013) find out through the research that as for vitality and market values, person-organization fit is positively related to employee performance. In view of this, this research is prone to a performance-based comprehensive view of behavior, believing that dependent variables of organizational performance shall cover the working abilities, attitudes and behaviors of employees. Therefore, this research proposes the hypothesis H3: Employee behavior is positively related to organizational performance.

Corporate culture affects value orientation of employees and the direction, way, strength and efficiency of their behavior, thus affecting the overall operating efficiency of the enterprise (Tian Fenfei, 2002). Yang Zhimin, Li Lan et al. (2005) point out that corporate culture can standardize employees and behavior of the enterprise and improve the business performance of the enterprise. Wang Lijuan (2006) also emphasizes that corporate culture can guide and shape attitudes and behaviors of employees, thus affecting the ultimate performance of the enterprise. Zhou $\mathrm{Ye}, \mathrm{Hu}$ Hanhui and Pan Ancheng (2006) believe that corporate cultural strength can guide, standardize, unite, encourage and radiate the enterprise, which is an important guarantee for the enterprise to obtain the sustainable competitive advantage. It can create extraordinary motives for employees and improve the performance of the enterprise. Yang Hao and Song Lianke (2013) believe that if an enterprise wants to increase the performance, it has to change its behaviors, which requires the guiding of the mindset. Maria (2016) believes that employee behavior is an important tool for corporate cultural force to affect organizational performance.

Nie Qingkai and He Haoming (2012) believe that corporate cultural strength is an "invisible hand" in the process of production, operation and management of the enterprise. It adjusts the management system of the enterprise through the consensus of all employees, coordinates management elements and increases the benefits of working efficiency and economic benefits. We believe that, the most successful strategic human resources management is to improve the employee performance ultimately by affecting the mentality of employees. There are many ways to change the mentality of employees, and corporate cultural strength is one of the most influential ways. While cohesion of corporate cultural strength enables group members to form common views and values, and it's easy for them to show consistent behaviors and work together for common goals. Performance can be improved by changing the behavior from the heart of employees through the establishment of a strategic human resources management model based on corporate cultural strength and the infiltration of corporate cultural strength, and characteristics of people are emphasized to truly realize people orientation. Organizational performance is reflected by summing up performance of all individuals in the organization to support the overall performance goals of the organization by relying on individual performance goals. It can be said that organizational performance is based on individual performance, and individual performance plays an intermediary role and affects organizational performance through employee behavior. Psychological contract constitutes the core of corporate cultural force, which directly affects behaviors of people in the organization, thus affecting organizational performance. Therefore, this research proposes the hypothesis H4: Employee behavior plays an intermediary role in the relationship between corporate cultural strength and organizational performance.

\section{Research design and data analysis}


This research has a scale for the measurement of each variable, and the scale of corporate cultural strength comes from the development of corporate cultural strength scale, which includes a total of 19 items, such as spiritual cultural strength, institutional cultural strength, behavioral cultural strength and innovative learning strength, etc. Employee behavior includes organizational commitment, organizational citizenship behavior and turnover intention, and its scale mainly refers to the scale proposed by Meyer \& Allen and Farth et al(1997). Organizational performance mainly includes financial performance and non-financial performance, and its scale mainly refers to the scale proposed by Xie Hongming and Chen Yantai et al(2006).

This paper collects data by using the cultural survey, and the seven-point Likert scale is obtained. To facilitate data collection and statistics, the electronic questionnaire is used, and there are a total of 500 questionnaires, 384 effective questionnaires are recovered finally. Then, collected data are used to carry out the reliability and validity analysis, correlation analysis and structural equation model analysis to verify research hypotheses.

Based on recovered effective questionnaires, SPSS 22.0 software is used to analyze data, and it's obtained that the Cronbach's value of reliability of the total scale is 0.947 , KMO value is 0.766 and Bartlett's value of significance test is 0.018 , indicating that questionnaire data have high reliability and validity. After using AMOS 20.0 for calculation, fit indexes of operating results are shown in Table 1. CFI and TFI are close to 1, and SRMR and RMSEA are close to 0, indicating that the model has a good goodness of fit.

Table 1 Goodness of Fit Index

\begin{tabular}{|c|c|c|c|c|c|c|}
\hline CFI & TFI & $\begin{array}{l}\text { Chi-squ } \\
\text { are }\end{array}$ & $\begin{array}{l}\text { Degree of } \\
\text { freedom }\end{array}$ & SRMR & RMSEA & $90 \% \mathrm{CI}$ \\
\hline $\begin{array}{c}\text { Comparativ } \\
\text { e fit index }\end{array}$ & $\begin{array}{c}\text { Tucker } \\
\text { Lewis Index }\end{array}$ & & & $\begin{array}{c}\text { Standardized } \\
\text { Root Mean } \\
\text { Square } \\
\text { Residual } \\
\end{array}$ & $\begin{array}{c}\text { Root Mean } \\
\text { Square Error } \\
\text { Approximati } \\
\text { on } \\
\end{array}$ & $\begin{array}{c}90 \% \\
\text { confidence } \\
\text { interval }\end{array}$ \\
\hline 0.925 & 0.912 & 265.758 & 146 & 0.060 & 0.094 & $0.076-0.112$ \\
\hline$>0.9$ & $>0.9$ & & & $<0.08$ & $<0.08$ & \\
\hline
\end{tabular}

The correlation analysis results show that: (1) In terms of the relationship between corporate cultural strength and organizational performance, the correlation coefficient of corporate cultural strength is 0.339 , the correlation coefficient of spiritual cultural strength is 0.398 , the correlation coefficient of institutional cultural strength is 0.210 and the correlation coefficient of innovative learning strength is 0.283 , indicating that corporate cultural strength is positively related to organizational performance. In terms of the analysis of the influence of corporate cultural strength on organizational performance, the $\mathrm{P}$ value is less than 0.05 , indicating that it's significant. (2) In terms of the relationship between corporate cultural strength and employee behavior, the correlation coefficient of employee behavior is 0.564 , the correlation coefficient of organizational commitment is 0.417 , the correlation coefficient of organizational citizenship behavior is 0.540 and the correlation coefficient of turnover intention is 0.353 , indicating that corporate cultural force is positively related to organizational commitment and organizational citizenship behavior. As reverse calculation is used for the calculation of all items of turnover intention, therefore, corporate cultural force is negatively related to turnover intention. In terms of the analysis of the impact of corporate cultural force on employee behavior, except for the turnover intention variable, all other $\mathrm{P}$ values are less than 0.05 , indicating significance. (3) In terms of the relationship between employee behavior and organizational performance, the correlation coefficient of employee behavior is 0.467 , the correlation coefficient of organizational commitment is 0.257 , the correlation coefficient of organizational citizenship behavior is 0.477 and the correlation coefficient of turnover intention is 0.364 , indicating that employee behavior is positively related to organizational commitment and organizational citizenship behavior. As reverse calculation is used for the calculation of all items of 
turnover intention, therefore, it takes on negative correlation. In terms of the analysis of the impact of employee behavior on organizational performance, the $\mathrm{P}$ value is less than 0.05 , indicating significance.

The mediating effect model test results show that: The mediation model fit index $X^{2} / \mathrm{Df}=1.2$, the $\mathrm{P}$ value is $0.256, \mathrm{CFI}=0.991, \mathrm{TFI}=0.986, \mathrm{RMSEA}=0.046$, and $\mathrm{SRMR}=0.029$. All actual values of the fit index meet the standards, indicating that the goodness of fit of sample data of the enterprise is acceptable. The $\mathrm{P}$ value is 0.038 , less than 0.05 , which is statistically significant, indicating the mediating effect. It can be seen from analysis results of the structural equation model of the mediating effect that organizational performance is taken as a dependent variable, first put in corporate culture and then put in employee behavior, finding that the relationship $(\beta=0.145)$ between corporate cultural force and organizational performance is greatly weakened before it is put in $(\beta=0.674)$, which indicates that employee behavior plays an intermediary role in the relationship between corporate cultural force and organizational performance, and the mediating effect is relatively significant $(\beta=0.655, \mathrm{P}=0.038)$.

\section{Conclusions and suggestions}

Corporate cultural strength is not built in one day, which shall be created by far-sighted founders and leaders of the enterprise and subtle influence of systems and standards with the joint efforts of all the employees. At the same time, corporate cultural strength can also be divided into multidimensional sub-cultural strength, and the management can start from different aspects to enrich the connotation of corporate cultural strength. Through research results, it's recommended that SMEs in Guangxi shall first bring advantages into play and stick to the original good ideas, and while achieving goals and values of the enterprise, SMEs shall achieve goals and values of employees, stabilize high-end talents of the enterprise with higher standards than industry standards and good growth and working environment and pay attention to the cultivation of talents inside the company, so that employees can fully give play to their abilities in the enterprise and be strongly satisfied with the enterprise. Specifically, we can focus on the following three aspects:

First, improve the connotation of corporate culture. Although enterprises have put forward the slogan that talents are the most important, relatively job-hopping still occurs. Therefore, it's suggested that while enriching the connotation of corporate culture, enterprises shall adhere to people-oriented, innovation-oriented and future inspiring connotation. Inside the company, insist on employee orientation and thoroughly penetrate the strength of corporate culture deeply into the hearts of employees, and during work, constantly enhance confidence of employees and cultivate the spirit of devotion and enterprise of employees, so that corporate cultural strength and employees are combined to achieve common development and progress.

Second, enhance the sense of identity of employees. First of all, it's recommended that enterprises shall establish platforms for employees to exchange with each other, and by optimizing the internal communication mechanism, various departments and staffs can communicate with each other. Regularly hold activities to further implement corporate culture. Second, enhance the consciousness for employees to participate in the construction of corporate cultural strength, and through active participation of employees, they gradually turn corporate values into their own values, so that employees can fully feel the sense of belonging and sense of achievement. At the same time, they will also realize their own life values and career plans, and practice the concept of corporate culture consciously.

Third, increase the construction of the assessment system. To establish the corporate culture assessment system is to standardize the overall construction of corporate culture, and the building of the assessment system shall be taken into account during construction. At the same time, it shall adapt to the objective reality of the enterprise. The cognitive level of employees can be assessed in terms of corporate culture, and the role of the publicity of cultural ideas advocated by enterprises can be played. 


\section{References}

[1] Rousseau D.M.Schema. Promise and Mutuality: The Building Blocks of the Psychological Contract [J].Journal Of Occupational and Organizational Psychology, 74(4):511-542.2001.

[2] Denison, and L. Rayna. Cultural traffic in Japanese anime: the meanings of promotion, reception and exhibition circuits in Princess Mononoke. Diss. University of Nottingham, 2005.

[3] Cascio F W. Managing Human Resource:Productivity,Quality of Work Life And Profits[M].New York:McGraw-Hill,Inc,1991.

[4] Bernadina, M. G., Hansen, W. E., Clercx, P., Henroteaux, M., \&Rutten, V. P. Neutrophil phagocyte dysfunction in a Weimaraner with recurrent infections. Journal of Small Animal Practice, 36(3), 128-31.1995.

[5] Nie Qingkai, \& He Haoming. Outline of Corporate Cultural Force. Enterprise Management Publishing House. 2012.

[6] Nie Qingkai, \& Zhao Qing. Literature review of the connotation, generation and functional system of corporate cultural force and its outlook. Foreign Economies and Management, 30(11), 51-56.2008.

[7] Chen Chunhua. From Concept to Practice: Enterprise Management, China Machine Press. 2016.

Wang Qin. Research on corporate cultural force in the Chinese management mode. Commodity and quality: Theoretical Research (S2), 135-136.2012.

[8] Brockbank, W., Ulrich, D., Yakonich, D.The new HR agenda: Human Resource Competency Study, University of Michigan Business School.2002.

[9] Yang Hongchang. Rational construction of corporate culture - reading The Corporate Cultural Survival Guide: Sense and Nonsense about Culture Change. Management World (6), 152-153.2003.

[10]Zhang Min, Chen Chuanming. Evolution of corporate culture theory from the perspective of strategic adjustment. Foreign Economies and Management, 27(3), 12-18.2005.

[11]Li Minghua. On the dynamic system of corporate cultural development. Management World (3), 208-209.1993.

[12](USA) William Ouchi. Theory Z - How American Management Can Meet the Japanese Challenge [M]. Social Sciences in China Press. 1984.

[13] Wang Zhen, Song Meng, \& Sun Jianmin. Real leadership: Concept, measurement, formation and effect. Advances in Psychological Science, 22(3), 458-473.2014.

[14]Tian Fenfei. Analysis of how corporate culture affecting the competitiveness of enterprises. Business Review (9), 58-61.2002.

[15] Yang Zhimin, Li Lan, Han Xiulan, Zheng Mingshen, Pan Jiancheng, Hao Dahai, etc. Construction of corporate culture: understanding, status quo and problems - A special survey report on the growth and development of Chinese entrepreneurs in 2005. Management World (6), 89-100.2005.

[16]Lijuan. Self-organizing analysis framework of corporate culture change. Management World (6), 155-156.2006. 
[17] Ye, Hu Hanhui, \& Pan Ancheng. Research on the relationship between psychological contract and corporate culture. Journal of Southeast University (Philosophy and Social Sciences), 8(5),27-30.2006

[18]Hao, Song Lianke. Research on the corporate cultural force mechanism - based on the perspective of strategic human resources management, Shanghai University of Finance and Economics Press. 2013.

[19] Eriksson Pernilla Ingelsson, "Building an organizational culture when delivering commercial experiences- the leaders' perspective", International Journal of Quality and Service Sciences, Vol. 8 Iss 2 pp.1-14.2016. 